\title{
Pesticide traces in local crops of Sancti Spíritus, Cuba: risk assessment study
}

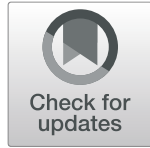

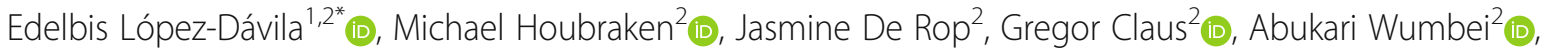 \\ Osvaldo Romero Romero ${ }^{1,3}$ and ander Spanoghe ${ }^{2}$ (i)
}

\begin{abstract}
Background: Vegetables and rice produced in Cuba may contain residue of pesticides that exceed the maximum residue limits (MRLs). Pesticide residues on crop samples from Sancti Spíritus province were analyzed. Based on these residue data, a risk assessment of consumer exposure was conducted.

Methods: Samples collected during the 2017, 2018, and 2019 periods were analyzed using UPLC-MS/MS and GC/ ECD chromatography techniques. A deterministic risk assessment was performed, using consumption data collected by the authors. Also, a probabilistic risk assessment was worked out with @RISK for the Monte Carlo simulation.

Results: A broad range of pesticides were detected in the samples. Most of the detected active ingredients were insecticides and fungicides. A considerable part of the detected pesticide residues exceeded the EU and Cuban MRLs. However, the deterministic risk assessment revealed that the consumer risk of pesticide exposure is low. Only in the maximum exposure scenario children and adults were exposed to methamidophos residues in tomatoes higher than the acceptable daily intake.

Conclusions: When a more realistic consumption (50th percentile) and higher (95th percentile) consumption pattern for tomatoes was assumed, the deterministic risk assessment found no chronic risk for children and adults being exposed to methamidophos present in the tomato samples. Furthermore, the probabilistic risk assessment concerning methamidophos exposure in tomato for children and adult strata showed no risk. To perform in the future a more accurate risk assessment for Cuban consumers it is important to have more detailed consumption data and an expanded dataset of the residues in different crops.
\end{abstract}

Keywords: Plant protection products, Vegetables, Chemical residues, Methamidophos, Endosulfan

\section{Introduction}

The use of synthetic pesticides worldwide has become a basic need for some crops to ensure quantity and quality (Kim et al. 2016; Souza Chaves et al. 2017). Pesticides have been a key factor in the fight against many plant diseases which has allowed access to high-quality food for a broader section of the population (Alonso-Hernández et al. 2015). It has been estimated that without

\footnotetext{
* Correspondence: edelbis86@gmail.com

${ }^{1}$ Study Center of Energies and Industrial Process, Sancti Spíritus University,

Avenida de Los Mártires \#360, CP 60100 Sancti Spíritus, Cuba

${ }^{2}$ Faculty of Bioscience Engineering, Ghent University, Ghent, Belgium

Full list of author information is available at the end of the article
}

synthetic pesticides a large amount of food production in the world can be lost (Räsänen et al. 2015). Despite the fact that pesticides are indispensable in current conventional agricultural practices, detectable levels of residues are present on the majority of foods in stores (JMPR 2015). Due to the adverse effects of certain active ingredients (AIs) on humans health and the environment (Wahid et al. 2017), the pesticide is therefore subject to the regulations (European Food Safety Authority 2014; Jeger et al. 2018; Markantonis et al. 2018).

In Cuba, to increase the productivity of agricultural systems, technological packages have been introduced 
whose main component is the use of synthetic pesticides (Fernandez et al. 2018). In the province of Sancti Spíritus, where agriculture is the main economic sector, its management is in line with the rest of the country. As described by Damalas and Koutroubas (2018) in their studies on agricultural development in developing countries, the need to increase yields of priority crops in the province to reduce imports led to the use of synthetic pesticides.

In a brief search was found that grain (rice), vegetables (mainly tomato), and tobacco are prioritized crops in the province agriculture, which receive a high amount of agrochemicals, i.e. synthetic pesticides (Fernandez et al. 2018; Perdomo Hernández et al. 2016). Coupled with the use of synthetic pesticides, mainly in fruits and vegetables, there is a constant concern in the local population regarding the risk to human health and the environment reflected in various journalistic studies. However, no recent study has been carried out assessing the content of synthetic pesticide in crops produced in Cuba farms, nor a health risk assessment has been conducted.

Previous studies, such as those conducted by Hernández et al. (2003a, 2003b) reported on residues in a large group of different crops from Havana province, Cuba (citrus, potatoes, cassava, plantains, rice, beans, tomatoes, peppers, cucumbers, garlic, onions, carrots, and beets). Other pesticide usage studies were published on rice crops (Hernández et al. 2003a, 2003b), tobacco, roots and tubers, grains and vegetables (del Puerto Rodríguez et al. 2014; Hernández Núñez and Pérez-Consuegra 2012).

Other old studies are focused on the adverse effects of pesticide poisoning and accidents, such as the one presented by González Valiente and Conill Díaz (1999), who report acute poisonings caused by pesticides in Cuba. González Valiente and Conill Díaz (1999) reported a total of 629 deaths due to pesticide exposure for the period 1990-1994 in Cuba. These figures accentuated the discrete upward trend observed since 1987 (González Valiente and Conill Díaz 1999). Organophosphate insecticides were the main class of pesticides responsible for these accidents. The population groups with the highest risk of death from exposure to organophosphates during agricultural activities were boys and adults. Then in 2001, González Valiente et al. made a second Cuban report on these pesticide incidents. They reported the death of 576 people due to the use, handling, suicide, or accidental poisoning (confuse the container with a food container) for the period 1995-1997. In this second report, again adult males were the most affected population group (63\%), and organophosphates the main class of pesticide involved.
Under the assumption that vegetables and rice produced in Sancti Spíritus province in Cuba contain amounts of pesticide residue exceeding the established norm, constituting a risk to the health of consumers. Pesticide residues on crop samples from Sancti Spíritus were analyzed. Based on the residue data, a risk assessment of consumer exposure to residues in Cuban vegetables and rice was conducted.

\section{Materials and methods Sampling}

Samples (Table 1) were collected in August 2017 (season with low vegetable production), January 2018 (season with high vegetable production), and May 2019 (season with medium vegetable production). Sampling took place in three municipalities with high agricultural activities (La Sierpe, Sancti Spíritus [same name as the province] and Cabaiguán, Fig. 1). The vegetable samples from Cabaiguán were obtained from the farms during harvest and from the local market. Around Sancti Spíritus there are two sample sites, La Quinta and Banao. All farms that had the vegetables of interest planted were visited. Within each sampling field (about $1 \mathrm{ha}$ ), five individual plants (collecting two fruits per plant) were sampled using an " $\mathrm{X}$ " sampling procedure and then pooled to obtain an individual composite sample. In the case of the local market, five tomatoes per each sales point visited were collected.

La Sierpe is a broad municipality with large rice fields. The rice samples for this study were taken mainly from three active places; Mapo, Peralejo, and Las Nuevas. From each one, a combined sample of $1 \mathrm{k}$ was collected, taking five random spikes (following an $\mathrm{X}$ principle) per plot (a quarter of a hectare) from the cultivated fields (10 ha). Due to scarce rainfall and thus accumulated water, no rice was planted in the sampling area in 2017 and 2019, therefore no samples could be collected in those years. However, the consideration of studying rice was maintained since it is one of the staple foods on the Cuban menu.

\section{Reagents and materials}

HPLC-grade acetonitrile (ACN) was supplied by BDH PROLABO (VWR International GmbH, Darmstadt, Germany), and $n$-hexane $>99 \%$ purity was obtained from Chem- Lab NV (Zedelgem, Belgium). Sigma-Aldrich (St. Louis, USA) supplied sodium hydrogencitrate

Table 1 Amount of samples collected of each crop per site

\begin{tabular}{llllll}
\hline Year & Tomato & Onion & Cucumber & Pepper & Rice \\
\hline 2017 & 10 & 4 & 2 & 5 & \\
2018 & 20 & 17 & 6 & 6 & 4 \\
2019 & 19 & & 5 & 10 & \\
\hline
\end{tabular}




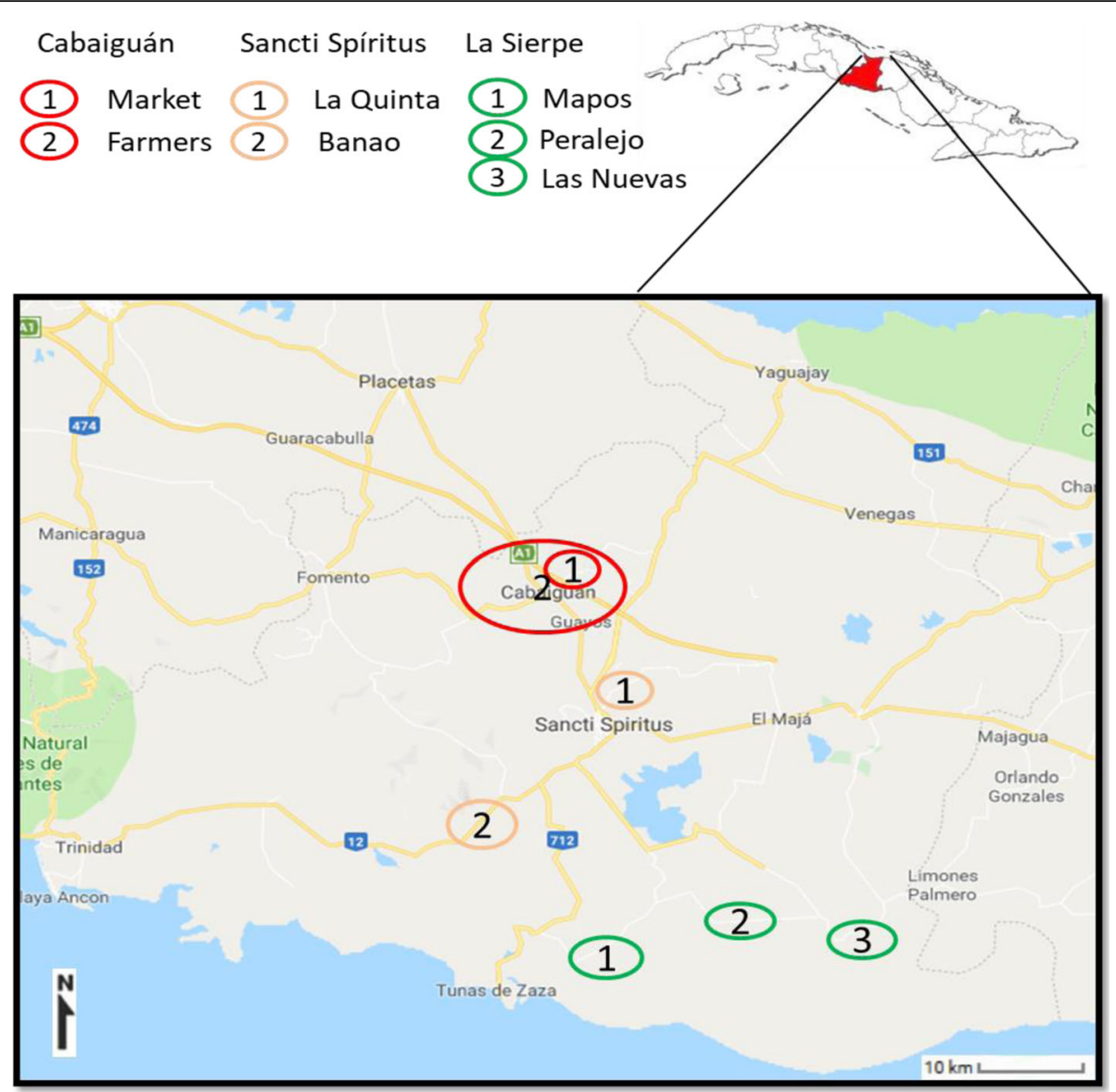

Fig. 1 Sampling sites in Sancti Spíritus province, Cuba. (Google maps)

Table 2 Processing factors (PF) considered in the study

\begin{tabular}{|c|c|c|c|c|c|c|c|}
\hline Active ingredient & Crops & Processing & PF & Active ingredient & Crops & Processing & PF \\
\hline alachlor & onion & cooked & $1^{\text {a }}$ & imidacloprid & cucumber & raw with peel & $1^{a}$ \\
\hline bifenthrin & onion & cooked & $1^{\mathrm{a}}$ & imidacloprid & sweet pepper & cooked & $1^{a}$ \\
\hline chlorothalonil & onion & cooked & $1^{a}$ & lindane & onion & cooked & $1^{c}$ \\
\hline chlorothalonil & tomato & raw with peel & $1^{\mathrm{a}}$ & lindane & cucumber & raw with peel & $1^{c}$ \\
\hline cyhalothrin & rice & cooked & $0.004^{\mathrm{a}}$ & methamidophos & tomato & raw with peel & $1^{\mathrm{b}}$ \\
\hline cypermethrin & sweet pepper & cooked & $0.71^{\mathrm{a}}$ & propiconazole & sweet pepper & cooked & $1^{a}$ \\
\hline cypermethrin & tomato & raw with peel & $0.88^{\mathrm{a}}$ & pyrimethanil & onion & cooked & $0.75^{d}$ \\
\hline difenoconazole & sweet pepper & cooked & $1^{\mathrm{a}}$ & pyrimethanil & cucumber & raw with peel & $0.75^{d}$ \\
\hline endosulfan & onion & cooked & $0.23^{b}$ & pyrimethanil & tomato & raw with peel & $0.7^{d}$ \\
\hline fenpropimorph & tomato & raw with peel & $1^{a}$ & tebuconazole & tomato & raw with peel & $0.78^{\mathrm{a}}$ \\
\hline imidacloprid & rice & cooked & $0.04^{\mathrm{a}}$ & & & & \\
\hline
\end{tabular}

${ }^{\mathrm{a}}$ (RIVM 2015)

${ }^{\mathrm{b}}$ (Tomer and Sangha 2013)

c(Holland et al. 1994)

${ }^{d}$ (Liang et al. 2013) 
sesquihydrate $\left(\mathrm{C}_{6} \mathrm{H}_{6} \mathrm{Na}_{2} \mathrm{O}_{7} \cdot 1.5 \mathrm{H}_{2} \mathrm{O}\right) \quad 99 \%$, sodium chloride $(\mathrm{NaCl})>99 \%$, sodium citrate tribasic dihydrate $\left(\mathrm{C}_{6} \mathrm{H}_{5} \mathrm{Na}_{3} \mathrm{O}_{7} \cdot 2 \mathrm{H}_{2} \mathrm{O}\right)>99 \%$, and the highest analytical purity pesticides standard. Magnesium sulfate $\left(\mathrm{MgSO}_{4}\right)$ anhydrous $\geq 98.0 \%$ came from Merck KGaA (Darmstadt, Germany).

\section{Sample preparation}

Once the samples were taken, they were prepared to be stored and to be transported to the Laboratory of Crop Protection Chemistry at Ghent University, Belgium, for analysis. Vegetables were cut into small pieces $\left(\sim 1 \mathrm{~cm}^{3}\right)$ and stored in $50 \mathrm{ml}$ centrifuge tubes and frozen ($20^{\circ} \mathrm{C}$ ). Rice (paddy) was also kept frozen. Once in the laboratory vegetable samples were crushed and homogenized with an Ultra-Turrax IKA T18 Basic (Metrohm N.V, Antwerpen, Belgium) apparatus. Rice samples were milled using a tabletop hammer mill (Glen Creston Stanmore 14-500S, London, England) and sieved by a $1.5 \mathrm{~mm}$ mesh.

\section{Sample analysis \\ Pesticide extraction}

The QUEChERS method (Quick, Easy, Cheap, Effective, Rugged, and Safe), a highly beneficial analytical approach that simplifies the analysis of multiple pesticide residues in fruit, vegetables, and cereals (Masiá et al. 2015; Rajapakse et al. 2018) was used. QUEChERS offers high recoveries for a very wide range of pesticides belonging to different chemical classes (Donkor et al. 2015; Kiljanek et al. 2016; Rajapakse et al. 2018). Two grams of dry milled rice and $10 \mathrm{~g}$ of vegetables of a homogenous made sample were weighed in standard centrifuge tubes $(50 \mathrm{ml})$. Milli-Q water was added until the dried samples of rice weighed $10 \mathrm{~g}$, then $15 \mathrm{ml}$ of $\mathrm{ACN}$ was added and this mixture was vigorously hand-shaken for $5 \mathrm{~s}$. The following salts were added to each sample to remove coextracted contaminants: $1.5 \mathrm{~g} \mathrm{NaCl}, 1.5 \mathrm{~g} \mathrm{C}_{6} \mathrm{H}_{5} \mathrm{Na}_{3} \mathrm{O}_{7}$. $2 \mathrm{H}_{2} \mathrm{O}, 0.750 \mathrm{~g} \mathrm{C}_{6} \mathrm{H}_{6} \mathrm{Na}_{2} \mathrm{O}_{7} \cdot 1.5 \mathrm{H}_{2} \mathrm{O}$ and $6.0 \mathrm{~g} \mathrm{MgSO}_{4}$. Samples were shaken for $5 \mathrm{~min}$ by $300 \mathrm{rpm}$ and centrifuged by Eppendorf 5804R Refrigerated Centrifuge (VWR International GmbH, Darmstadt, Germany) for 5 min at $10000 \mathrm{rpm}$.

The solvent exchange is different for the UPLC-MS/ MS (polar) and GC-ECD (nonpolar) samples. For the UPLC-MS/MS samples, $1 \mathrm{ml}$ of the upper layer was sampled and added to a volumetric flask of $10 \mathrm{ml}$. Milli$Q$ water $(9 \mathrm{ml})$ was added to obtain a total volume of 10 $\mathrm{ml}$. A subsample of $\pm 1.5 \mathrm{ml}$ was pipetted in a UPLCMS/MS vial. For the GC-ECD samples, $5 \mathrm{ml}$ of the upper layer was sampled to an evaporation bowl. The solvent $(\mathrm{ACN})$ was evaporated in the rotary evaporator (Buchi SL 200, Essen, Germany) and $5 \mathrm{ml}$ of $\mathrm{n}$-hexane was added to the bowls to redissolve the analyte. A subsample of $\pm 1.5 \mathrm{ml}$ was pipetted in a GC-ECD vial.

\section{Ultra-performance liquid chromatography operating conditions}

A Waters ACQUITY UPLC ${ }^{\mathrm{mm}}$ (Zellik, Belgium), equipped with a quaternary pump and triple quadruple system with electrospray ionization (Waters $\mathrm{Xevo}^{\circ} \mathrm{TQD}$ ) to perform sample analyses were used. The separation column, an ACQUITY UPLC BEH C18, $130 \AA(1.7 \mu \mathrm{m} \times 2.1$ $\mathrm{mm} \times 50 \mathrm{~mm})$ was kept at $40^{\circ} \mathrm{C}$. A sample $(10 \mu \mathrm{l})$ was automatically injected. The mobile phase components were (A) Milli-Q water with $0.1 \%$ formic acid and (B) $\mathrm{ACN}$ with $0.1 \%$ formic acid. A flow rate of $0.4 \mathrm{ml} \mathrm{min}^{-1}$ of $98 \%$ mobile phase A for 0.25 min was used as a gradient set. From $0.25 \mathrm{~min}$ to $7 \mathrm{~min}$, a linear gradient was used up to $98 \%$ mobile phase B, held for $1 \mathrm{~min}$. Then a linear gradient was used to $98 \%$ mobile phase A and held for $1 \mathrm{~min}$. The capillary needle was maintained at + $2 \mathrm{kV}$, curtain gas $\left(\mathrm{N}_{2}\right)$ at 7 bars, and temperature $500{ }^{\circ} \mathrm{C}$. The AIs were monitored and quantified using multiple reactions monitoring (MRM). Two different $\mathrm{m} / \mathrm{z}$ transitions were selected for each analyte. The MS/MS-transitions, ionization mode, cone voltage, and collision energy are given in Supplementary Materials 1.

\section{Gas chromatography with electron capture detection}

An Agilent Technologies $6890 \mathrm{~N}$ gas chromatograph equipped with an Agilent Technologies 7683 Series autosampler injector, coupled to an electron capture detector (GC-ECD) was used. Separation was performed on a HP-5MS (5\% phenyl methyl siloxane) capillary column $(30 \mathrm{~m} 0.25 \mathrm{~mm} 0.25 \mu \mathrm{m})$. As operating conditions, the column was initially set at a temperature of $60^{\circ} \mathrm{C}$ and then the oven temperature was increased at a rate of $20^{\circ} \mathrm{C} \mathrm{min}-1$ to $150^{\circ} \mathrm{C}$. After that, it was increased at a rate of $15^{\circ} \mathrm{C} \mathrm{min}^{-1}$ to $250^{\circ} \mathrm{C}$, held for $2 \mathrm{~min}$ at $250^{\circ} \mathrm{C}$, followed by an increase at a rate of $30^{\circ} \mathrm{C} \mathrm{min}^{-1}$ to $270{ }^{\circ} \mathrm{C}$ and held constant for $10 \mathrm{~min}$ at $270^{\circ} \mathrm{C}$. Thereafter, it was increased at a rate of $30^{\circ} \mathrm{C} \mathrm{min}^{-1}$ to $280^{\circ} \mathrm{C}$ and finally, it was held at $280^{\circ} \mathrm{C}$ for $11 \mathrm{~min}$. Injector and detector temperatures were maintained at $200^{\circ} \mathrm{C}$ and $250^{\circ} \mathrm{C}$, respectively. Helium was used as a carrier gas at a flow rate of $1.1 \mathrm{ml} \mathrm{min}^{-1}$ and the injections were made in the split mode with a split ratio of 52.7:1.

To test selectivity, individual standard solutions, and mixed standard solutions (5 for UPLC-MS/MS and 1 mixture for GC-ECD) were injected. The accuracy was evaluated using the spiked-placebo recovery method (Bernal 2014; DG SANTE 2018). Vegetables (tomato, onion, cucumber, and pepper) and rice were spiked eight times at a high $\left(100 \mu \mathrm{l} \times 10 \mathrm{mgl}^{-1}\right)$ and a low $(100 \mu \mathrm{l} \times 1$ $\mathrm{mgl}^{-1}$ ) concentration to determine the recovery at the maximum and the minimum amount of the AIs 
expected in the samples. Linearity was determined using linear regression of the calibration curve from five concentration levels $\left(0.004,0.01,0.02,0.04\right.$ and $0.1 \mathrm{mgl}^{-1}$ ). The obtained recoveries were expressed in percentage. Values were corrected if the recoveries were below $70 \%$ or above $120 \%$.

The limit of quantification LOQ and detection limit LOD were calculated by multiplying the standard deviation from the eight blanks replicates by 10 and 3, respectively, using the $t_{99 s L L M V}$ (lowest limit of method validation) method (Bernal 2014). LOQ was set up as $0.001 \mathrm{mg} \mathrm{l}^{-1}$ for the AIs analyzed by the UPLC-MS/MS and $0.01 \mathrm{mgl}^{-1}$ for those analyzed by the GC-ECD, and LOD was $0.0003 \mathrm{mgl}^{-1}$ and $0.003 \mathrm{mgl}^{-1}$ respectively. The pesticide residues detected in the samples were compared with the MRL values. The Cuban MRLs were obtained from the Cuban National Bureau of Standards (2012) and the European MRLs come from the EU Pesticides database (European Commission 2016).

\section{Dietary survey}

To perform a risk assessment of consumer exposure to pesticide residues in vegetables and rice grown in Sancti Spíritus, it is necessary to know, in addition to the residue data on these crops, the intake levels of the crops by the local population. A descriptive consumption data of vegetables and rice were collected at random from 462 people in different neighborhoods of the province. The equation of Cochran (1977) was applied for the calculation of this sample size. Data were separated by strata (six age classes): toddlers ( $0-4$ years old), children (5-14 years old), adolescents (15-24 years old), adults (25-64 years old), elderly (65-76 years old) and very elderly (77 years old and over) according to Cuban standards (ONEI 2019). Intake data were collected from a two-time 24-h recall interview conducted by trained interviewers through a face-to-face interview. This concerns a dietary recall method used to collect consumption data, which involves asking the consumers to recall the actual food intake for the past $24 \mathrm{~h}$ or the previous day. This recall was made during two non-consecutive days in 2 weeks. The average of both days of recall was used to estimate the daily vegetable and rice consumption. The consumption data results are shown in Supplementary Materials 2 . In the calculation of the amount of food from the portion sizes and recipes declared by the consumer in the survey, the following assumptions were considered:

- Average weight (the weight of five crops divided by five): sweet pepper $2.5 \pm 0.2 \mathrm{~g}$, onion $10 \pm 0.8 \mathrm{~g}$, cucumber $350 \pm 26.0 \mathrm{~g}$, and tomato $108 \pm 5.0 \mathrm{~g}$.

- Onion recipe factor $=0.067$ (average of bean soup consumed $(200 \mathrm{ml})$ by one person, divided by the total volume of soup prepared $(3000 \mathrm{ml}))$. In the case where the onion was consumed in another receipt, the value of its mass described above was taken into account. In all cases, it was multiplied by the total number of onions declared as consumed by the interviewee and in its variants.

- Sweet pepper recipe factor (soup ratio 0.067 multiplied by the average of sweet pepper declared as used as portion size per strata $=0.068$ for toddlers, 0.13 for children, adolescents, and very elderly, and 0.27 for adults and elderly.

Based on the cooked rice consumption portion size data collected, it was assumed $250 \mathrm{~g}$ of cooked rice as the maximum portion size for toddlers and very elderly people, $400 \mathrm{~g}$ was considered for children, and $500 \mathrm{~g}$ for adolescents, adults, and elderly. The average (rice and vegetable) daily consumption ( $\mathrm{kg}$ food $\mathrm{kg}^{-1} \mathrm{BW}$ day ${ }^{-1}$ ) was calculated from the frequency of daily intake $(\mathrm{kg}$ food day ${ }^{-1}$ ), portion sizes, recipes or processing, and the $\mathrm{kg}$ body weight (BW) per day for each person.

\section{Risk assessment}

The consumption data and the residue concentration data were used to assess chronic consumer exposure to pesticides. The residue levels of some of the individual AIs in the vegetable samples were low, below the LOQ. Therefore, for the chronic exposure assessment a pessimistic approach was adopted (worst case scenario). This means that for the AI selected for the assessment, a LOQ value was used for the non-quantified residues and LOD for the non-detects. The estimated exposure was compared to ADI (acceptable daily intake) of the AI resulting in a ratio. To estimate the consumer's level of safety (Mekonen et al., 2015) the ratio was evaluated against the reference value of one. If the ratio was higher than one, it indicated that ADI was exceeded for that particular AI and that in turn there is a potential risk of exposure to the AI. A cumulative scenario was evaluated for AIs with the same mode of action, detected in the same crop or several of those evaluated, adding their exposure value per strata (toddler, children, adolescents, ...), per year.

With each selected AI, one exposure was assessed for each of the six age classes (scenario), based on three sub-scenarios: minimum (least realistic), medium (realistic), and maximum (worst case). The deterministic exposure was carried out based on a single point estimation, minimum exposure scenario (P5), median exposure scenario (P50), and maximum exposure scenario (P95) using Eq. 1. In this regard, the minimum, median, and maximum consumption values of vegetables and rice $\left(\mathrm{kg} \mathrm{kg}^{-1} \mathrm{BW}\right.$ day-1) were respectively 
multiplied by the minimum, median, and maximum concentrations of the AI detected as in Mekonen et al. (2015).

$$
\begin{aligned}
& \text { Exposure }\left(\frac{\mathrm{mg} \text { Active ingredient }}{\mathrm{kg} \mathrm{BW} \times \text { day }}\right) \\
& =\text { consumption }\left(\frac{\mathrm{kg} \text { vegetable or rice }}{\mathrm{kg} \mathrm{BW} \times \text { day }}\right) \\
& \times \text { residue }\left(\frac{\mathrm{mg} \text { Active ingredient }}{\mathrm{kg} \text { vegetable or rice }}\right)
\end{aligned}
$$

The detected pesticide residue values were corrected according to the appropriate process factors (Table 2). For example, rice is cooked, onion and sweet pepper are cooked in soup or meat sauce and tomato and cucumber are washed (Holland et al. 1994; Keikotlhaile et al. 2010; Liang et al. 2013; Markantonis et al. 2018; Scholz et al. 2016; Scholz et al. 2018; Tomer and Sangha 2013). Based on the answers of the interviewees and the preference of the population, only raw tomatoes were considered, not their variants (soup, pasta, or pure ...). The values of processing factors are mainly according to the compilation of the Netherland National Institute for Public Health and the Environment (RIVM 2015). Others source also use are the studies from Holland et al. (1994), Liang et al. (2013) and Tomer and Sangha (2013),

In the case of obtaining the deterministic assessment a result that requires a more accurate analysis, a probabilistic assessment has been performed. The probabilistic analysis will follow the same methodology as the deterministic analysis, with each AI selected, independent of the crop, and exposure assessment will be made for each of the six age classes (scenarios), based on three subscenarios: minimum, medium, and maximum. In this way, individual risk can be assessed. Additionally, other analyses such as adding up the intake of various crops with residues of the same AI per age classes or adding up the exposure of AIs with the same MoA will also be performed. The probabilistic assessment of chronic risk is conducted with @RISK 7 (Palisade Corporation, USA), an add-in for Excel (Jeger et al. 2018; Mekonen et al., 2015), in which the consumption ( $\mathrm{kg}$ food $/ \mathrm{kg} \mathrm{BW}$ day) and residue (mg A.I $/ \mathrm{kg}$ food) distributions are combined into an exposure distribution ( $\mathrm{mg} \mathrm{AI} / \mathrm{kg} \mathrm{BW}$ day). In contrast to the deterministic approach, in the probabilistic assessments, suitable parametric distributions are fitted to the residues and the consumption data. Further information regarding @risk software and its operation is described in Supplementary Materials 3.

\section{Statistical analysis}

The absolute and relative frequencies expressed in percentages of each of the categories of the described variables were calculated. The Statistical Package for Social
Sciences (SPSS) program (IBM Corp, v. 20. Armonk, NY, USA) was used. The Paired Samples T-test $(p<$ 0.05 ) was used to evaluate differences in pesticide group between years, and the significant differences between the population strata (toddlers, children, adolescents, adults, elderly, and very elderly) concerning pesticide exposure.

\section{Results and discussion \\ Pesticide residue in crops}

The residues range found using the LC-MS/MS and GC-ECD technique is given in Tables 3 and 4 respectively, full tables are in Supplementary Materials 4 and 5 . The corresponding MRLs are shown at the bottom of the tables. In $18 \%$ of the analyzed samples $(n=106)$ no residue was detected. The majority of the samples $(27 \%)$ contained three different AIs. At least one AI was detected in $14 \%$ of the samples, and up to six different AI residues were detected in $8 \%$ of the samples.

From the herbicides, only residues of one AI (alachlor) were detected. No significant differences were found between the frequency of the detection of fungicide and insecticide residues present in $2017(p=0.389)$ and 2018 $(p=0.680)$ vegetable samples. However, in 2019 there was a significant difference between the number of insecticides and fungicides residues detected (the difference does not include $0(95 \% \mathrm{CI})$, therefore the $p$-value of the T-test is $<0.05)$. Secondly in the T-test analysis between the total concentrations of fungicides and insecticides per year, no significant differences were found (2017 $p=0.102,2018 p=0.764$, and $2019 p=0.979)$. The study with these results demonstrates that regardless of the year, total fungicide and insecticide residues are equally present in the vegetable samples. In 2017 the organophosphates methamidophos, acephate, and the organochlorine endosulfan, all have been banned for more than a decade in Europe (FAO/UNEP 2007, 2015), were detected. In 2018 the presence of methamidophos and endosulfan residues persisted. Lindane as well as alachlor, also banned in Europe, was detected that year. In 2019 residues of acephate were found again, and of two other AI banned in Europe (dimethoate and fenpropimorph). Also, cypermethrin, pyrimethanil, imidacloprid, tebuconazole, and azoxystrobin were detected in samples from all three sampling periods. Tomatoes contained most pesticide residues. In vegetables, $49 \%$ of the pesticides were detected in tomatoes (139) and 26\% in onion (73) (whole data in Supplementary Materials 4 and 5).

It was also recognized by farmers that tomato and onion cultivation results in the greatest economic benefits. Also, farmers mentioned in the interview that motivated by the great economic benefit they overuse pesticides to guarantee the highest possible yield. 


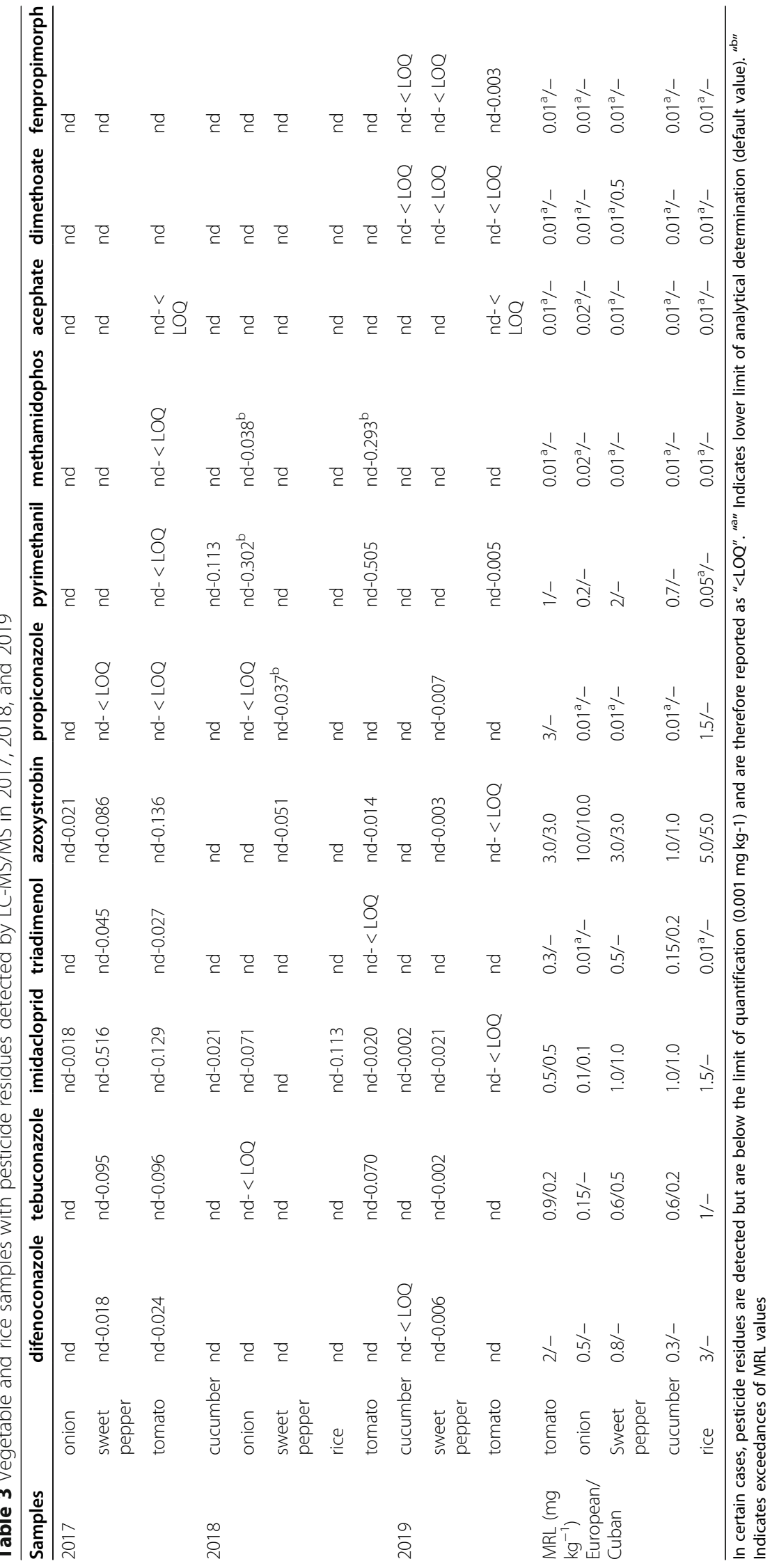


Table 4 Vegetable and rice samples with pesticide residues detected by GC-ECD in 2017, 2018, and 2019

\begin{tabular}{|c|c|c|c|c|c|c|c|c|}
\hline Samples & & lindane & chlorothalonil & alachlor & bifenthrin & $\lambda$-cyhalothrin & cypermethrin & endosulfan \\
\hline \multirow[t]{4}{*}{2017} & cucumber & nd & nd & nd & nd & nd & 0.029 & nd \\
\hline & onion & nd & nd & nd & nd & nd & $\mathrm{nd}-0.440^{\mathrm{b}}$ & nd \\
\hline & sweet pepper & nd & nd $-<$ LOQ & nd & nd-0.026 & nd & nd-0.171 & nd \\
\hline & tomato & nd & nd-0.123 & nd & nd-0.030 & nd & nd-0.024 & nd- $<$ LOQ \\
\hline \multirow[t]{5}{*}{2018} & cucumber & nd $-<$ LOQ & nd & nd- $0.204^{b}$ & nd & nd & nd & nd \\
\hline & onion & $n d-0.242^{b}$ & nd- $-0.291^{b}$ & $\mathrm{nd}-2.905^{\mathrm{b}}$ & nd-0.063 & nd & nd & nd-0.069 \\
\hline & sweet pepper & nd & nd & nd & nd & nd-0.027 & nd & nd \\
\hline & tomato & nd & nd-0.71 & $n d-1.633^{b}$ & nd & nd & nd-0.046 & nd-0.010 \\
\hline & rice & nd & nd & nd & nd & nd-0.089 & nd & nd \\
\hline \multirow[t]{3}{*}{2019} & cucumber & nd & nd & nd- $0.018^{b}$ & nd & nd & nd-0.016 & nd \\
\hline & sweet pepper & nd & nd & nd & nd & nd & nd-0.064 & nd \\
\hline & tomato & nd & nd-0.105 & nd & nd & nd & nd & nd \\
\hline \multirow[t]{5}{*}{ MRL $\left(\mathrm{mg} \mathrm{kg}^{-1}\right)$ European/Cuban } & tomato & $0.01^{\mathrm{a}} /-$ & $6.0 / 5.0$ & $0.01^{\mathrm{a}} /-$ & $0.3 /-$ & $0.1 / 0.3$ & $0.5 / 0.2$ & $0.05^{\mathrm{a}} /-$ \\
\hline & onion & $0.01^{a} /-$ & $0.01^{\mathrm{a}} / 0.5$ & $0.02^{a} /-$ & $0.01^{a} /-$ & $0.2 / 0.2$ & $0.1 / 0.01$ & $0.1^{\mathrm{a}} /-$ \\
\hline & sweet pepper & $0.01^{a} /-$ & $0.01^{\mathrm{a}} / 7.0$ & $0.01^{a} /-$ & $0.5 /-$ & $0.1 / 0.3$ & $0.5 / 0.1$ & $0.05^{a} /-$ \\
\hline & cucumber & $0.01^{a} /-$ & $5.0 / 5.0$ & $0.01^{\mathrm{a}} /-$ & $0.01^{a} /-$ & $0.1 / 0.05$ & $0.2 / 0.07$ & $0.05^{a} / 1.0$ \\
\hline & rice & $0.01^{a} /-$ & $0.01^{\mathrm{a}} /-$ & $0.01^{\mathrm{a}} /-$ & $0.01^{\mathrm{a}} /-$ & $1.0 / 1.0$ & $2.0 / 2.0$ & $0.05^{a} /-$ \\
\hline
\end{tabular}

In certain cases, pesticide residues are detected but are below the limit of quantification $(0.01 \mathrm{mg} \mathrm{kg}-1)$ and are therefore reported as " $<\mathrm{LOQ}$ ". "ä" Indicates lower limit of analytical determination (default value). "b" Indicates exceedances of MRL values

This study finding high levels for some products, confirms that synthetic pesticides are still in use in vegetable production in Cuba. Of the samples, $31 \%$ contained at least one AI above the European MRL (most Cuban MRLs are missing, which difficulty a national analysis). This is despite previous Cuban studies which have warned of the adverse consequences of synthetic pesticides on human health and the environment (Figueroa González and Pérez-Consuegra 2012; Hernández Contreras et al. 2010; Hernández Núñez and Pérez-Consuegra 2012; Hernández et al. 2003a, 2003b; Perdomo Hernández et al. 2016; Vega Bolaños et al. 1997).

In the onion samples, the following AIs were quantified: alachlor, pyrimethanil, chlorothalonil, azoxystrobin, cypermethrin, bifenthrin, imidacloprid, methamidophos, lindane, and endosulfan. Six of the ten AIs are insecticides; three are fungicides and one is the herbicide alachlor. Endosulfan and lindane have the same mode of action (MoA) and this also applies to bifenthrin and cypermethrin (IRAC 2019). They should be alternated with AIs with another MoA to prevent resistance development (IRAC 2019; Sparks and Nauen 2015).

In tomato samples, the following AIs were quantified: pyrimethanil, azoxystrobin, tebuconazole, imidacloprid, methamidophos, difenoconazole, triadimenol, bifenthrin, chlorothalonil, cypermethrin, and fenpropimorph. Seven out of the eleven AIs are fungicides, the others are insecticides. Except for methamidophos, the other AIs present in the samples were lower than the established
MRLs. Due to the warm climate of the province of Sancti Spíritus (annual average $25.7^{\circ} \mathrm{C}$, summer $30.1{ }^{\circ} \mathrm{C}$, and winter $21.0^{\circ} \mathrm{C}$ ) with high relative humidity (annual average $78 \%$ ), the pressure of fungal infection is high (Harel et al. 2014; Rawat 2015; Shamshiri et al. 2018). This is one of the reasons why farmers prefer to grow vegetables during winter (Ayyogari et al. 2014; Hernández Córdova and Soto Carreño 2012). It is also important to draw some attention to the fact that tebuconazole, difenoconazole, and triadimenol have the same MoA (FRAC 2018). Methamidophos is the only AI found in tomatoes that is no longer allowed to be used in Europe and the USA (FAO/UNEP 2015; Roberts and Routt Reigart 2013) and its use is also no longer allowed in the updated Cuban official list of authorized pesticides from 2016 (Registro Central de Plaguicidas 2016). Methamidophos was allowed to be used until 2016; the presence of methamidophos in the samples (from 2018) demonstrates unauthorized use. No previous reports of pesticide residues in Cuban tomatoes were found in the last decade. Before, Hernández et al. (2003a, 2003b) have reported an average concentration of methamidophos of $67 \mu \mathrm{g} \mathrm{kg}-1$ in tomatoes, similar to the average value quantified in this study $\left(73 \mu \mathrm{g} \mathrm{kg}^{-1}\right)$. Hernández et al. (2003) also have reported average values of dimethoate and carbaryl of $75 \mu \mathrm{g}$ $\mathrm{kg}^{-1}$. In this study, dimethoate $(<\mathrm{LOQ})$ was found in tomatoes and cucumbers. Furthermore, Hernández et al. (2003a, 2003b) have reported average values of methamidophos in sweet pepper $\left(270 \mu \mathrm{gg}^{-1}\right)$. 
In 2017 residues of two samples (18\%) exceeded the MRL. This was observed for cypermethrin in onion (Cuban National Bureau of Standards 2012; JMPR 2015). For 2018 a higher percentage (65\%) of exceedances was found. Then in 2019, the percentage of exceedances decreases again to only one AI, alachlor in cucumber. Alachlor is approved for use in Cuba (Registro Central de Plaguicidas 2016) on corn, beans, soya beans as well as on tobacco, but not in vegetables where it was found in this study. No MRL for alachlor is registered in the Cuban MRL database (Cuban National Bureau of Standards 2012). The residue of methamidophos and lindane, AIs which are banned for use in Europe, exceeded the European MRLs. The Cuban norm which registers the pesticide MRLs in food dates from 2012 (Cuban National Bureau of Standards 2012), and although both methamidophos and lindane were authorized for use at that time, (Lista Oficial de plaguicidas autorizados. Republica de Cuba 2008), no MRLs for methamidophos and lindane in vegetables were established (Cuban National Bureau of Standards 2012). As part of the national program to reduce the use of highly toxic AI, in the latest list of authorized pesticides in Cuba, dating from 2016 (Registro Central de Plaguicidas 2016), methamidophos and lindane do not appear anymore. In contrast to what was found in the samples, where it is evident that farmers maintain stocks of these products or due to its persistence in the soil some of these residues can still be detected today.

Endosulfan is still present on the list under restricted authorization use, mainly for coffee. It can also be used in onion, garlic, cucurbits, tomato, and sweet pepper. In the case of chlorothalonil, the residues quantified in onion samples exceeded the corresponding European MRL limit value $\left(0.01 \mathrm{mg} \mathrm{kg}^{-1}\right)$. This was not the case for the Cuban MRL values $\left(0.5 \mathrm{mg} \mathrm{kg}^{-1}\right.$ ) (Cuban National Bureau of Standards 2012). The same was observed for bifenthrin. Pyrimethanil was present in 2018 samples. In the region of Sancti Spíritus, pyrimethanil is authorized for use in banana crops to treat the Sigatoka spp. (Mycophaerella spp.), nevertheless, it is not authorized in vegetables.

In addition, few AIs (two) were found in the paddy rice and their concentrations were low (ten times lower than the corresponding MRL). The detected results were in correspondence with those reported by Teló et al. (2017) in Brazil. Also in previous studies from Barik et al. (2010) and Teló et al. (2015), no residues of imidacloprid and cyhalothrin were found in the rice grains cultivated under GAP.

The table is larger than the page length, the table is placed on page 34, as journal guidelines suggest. The table should appear in this location in the text file during production.
The table is larger than the page length, the table is placed on page 35 , as journal guidelines suggest. The table should appear in this location in the text file during production.

\section{Consumer risk assessment}

As seen in Section 3.1, 25\% of the quantified pesticide residues exceed the European and Cuban MRLs. The MRL is a value used to determine if a product can be placed in the market or not according to Good Agricultural Practices (it is related to food trade). It is not a toxicological safety limit such as ADI or ARfD, which indicates a health concern (Brancato et al. 2018; JMPR 2015). Therefore as long as exposure is estimated to be below the ADI or ARfD there is no perceived risk for the consumer. The vegetables and rice produced in Cuba are only for local consumption and do not go to foreign markets; therefore exceedances of the MRL in Cuba do not imply a real trade problem.

Vegetable consumption (Supplementary Materials 2) is low, only $42.4 \%$ of the surveyed population (average of both interview days) declared to have consumed at least one of the four vegetables evaluated (prevalent vegetables in the region). Mulet Pascual (2017) pointed out that the vegetable price increase is one of the main causes of the vegetable consumption decrease $(1 \mathrm{k}$ of tomatoes, cucumbers, onions, and sweet peppers respectively purchased in-state establishments represents 3.9\% of the average salary "752 pesos" (Gaceta Oficial de la República de Cuba, Ministerio de Finanzas y Precios 2016)). An average household spends between 74 and $79 \%$ of their monthly income only on food (García Álvarez et al. 2014). Besides, the statistical yearbooks indicate a decrease in the total sales of vegetables from $97.9 \%$ (total sales in 2017 respect to 2016) to $60.1 \%$ in thousands of pesos for the period 2018-2019, in the same sampling period (January-June) (ONEI 2017, 2019). Furthermore, the residue dataset is limited, due to not all possible IAs having been explored, for example, those used in fruits, other grains, or tobacco (Perdomo Hernández et al. 2016) or temephos in potable water (George et al. 2015). The accumulated risk of all the present AIs can imply a higher risk for consumers.

\section{Deterministic}

Residue data of 15 from the 18 AIs detected (Supplementary Materials 6) and consumption data of 462 people (Supplementary Materials 2) were used in the deterministic chronic dietary exposure assessment. The rest of the AIs (triadimenol, acephate, and dimethoate) were not considered, as there were more undetected (< LOD) than detected results. Further on, for several of the AI selected for the deterministic consumption exposure assessment (six different age classes: toddlers, 
children, adolescents, adults, elderly, and very elderly), only their maximum percentile (p95) have been considered in the evaluation since their median (p50) and minimum (p5) consumption values are zero and residual data concentrations are below the LOQ. These cases include azoxystrobin and tebuconazole in 2017, alachlor, endosulfan, chlorothalonil, tebuconazole, bifenthrin, imidacloprid, and cyhalothrin in 2018, and propiconazole, chlorothalonil, and cypermethrin in 2019.

Figure 2 shows the results of the consumer deterministic chronic risk assessments (ADI exceedance), for the samples collected in 2017, 2018, and 2019. Since most of the risk values obtained are very low, it was decided to show in Fig. 2 only those that were equal or higher than 0.01 (only observed in maximum scenarios). Therefore, all the results of the minimum and median scenario evaluations, as well as many other maximum scenarios, from the six different age classes studied, were left out of Fig. 2. The detailed risk assessment results derived from the exposure analysis for each scenario with its $\mathrm{ADI}$ reference value, depending on the $\mathrm{AI}$ and the crop assessed, are provided in the tables of Supplementary material 7.

The T-test analysis performed showed that there were no significant differences $(p=0.555)$ between the strata (toddlers, children, adolescents, adults, elderly, and very elderly) concerning pesticide exposure via vegetable consumption, with an exception of methamidophos in tomatoes. The rest of the scenarios (other AIs and analyzed crops) showed that the evaluated strata are out of risk (exposure [minimum, medium and maximum] value below ADI indicated no health concern) (Fig. 2). Even if the risk indicators of the AIs with the same MoA are added in a combined diet (cumulative), such as is the case for endosulfan and lindane in onions and cucumbers, the pyrethroids cypermethrin, bifenthrin and $\lambda$-cyhalothrin in tomato, onion, and rice, chlorothalonil in tomato and onions, difenoconazole and propiconazole in sweet pepper and imidacloprid in sweet pepper and cucumber, there is a negligible human exposure risk. Figure 2 shows that only for the maximum exposure scenario of children, and adults a risk to methamidophos is seen due to the consumption of tomatoes from the 2018 period samples; children 2.3, and adults 1.2 times above the ADI. If it is considered that a maximum exposure scenario is the worst case (see Supplementary Materials 2 crop consumption), very few consumers ( 3 children and 17 adults) are exposed to higher levels than the ADI.

The hypothesis was that the average exposure scenario should be more realistic. However, due to the limitations of the low number of respondents and low consumption (more than $50 \%$ of the respondents did not consume vegetables) (Supplementary Materials 2), it was shown that it was not realistic enough.

To be able to assess realistic chronic exposure and risk for children and adults exposed to methamidophos residues in tomatoes, one assumption was made: increased tomato consumption. This is finally an additional exposure scenario; median exposure to hypothesized higher tomato consumption. To reach the median toxicological

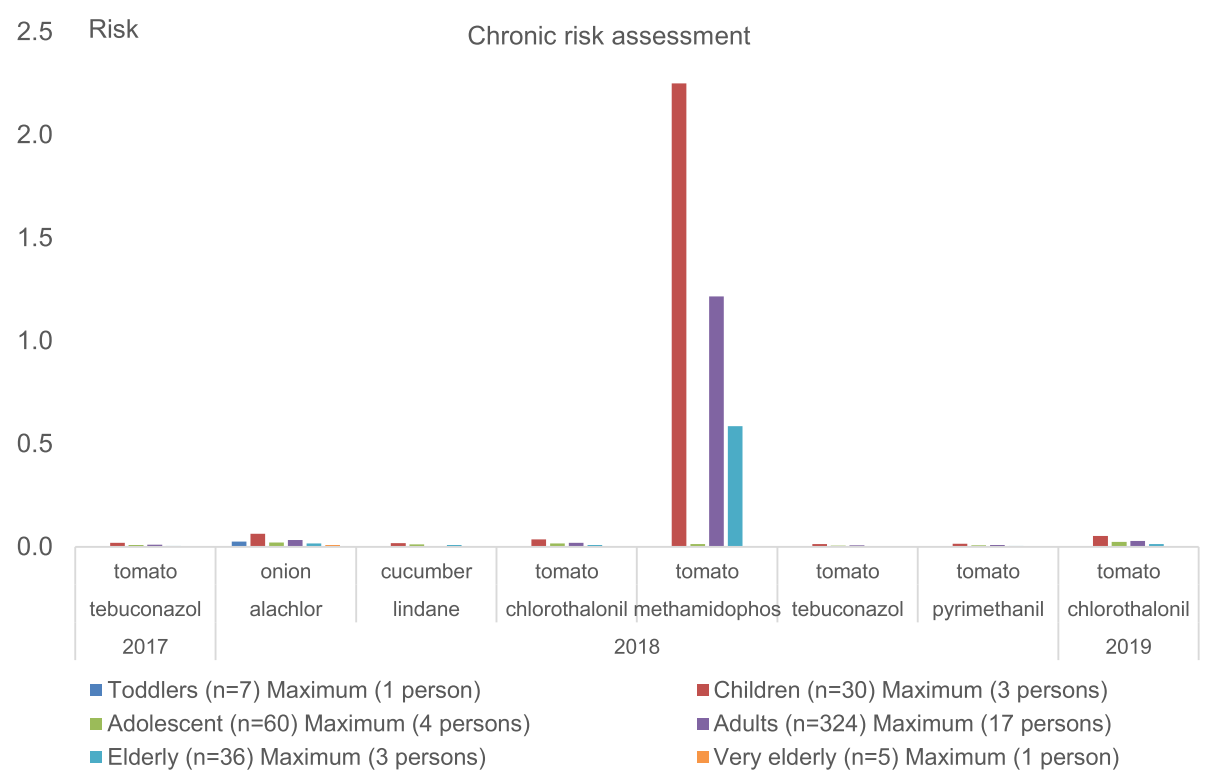

Fig. 2 ADI exceedance (chronic risk) of Cuban consumers (six different age classes: toddlers, children, adolescents, adults, elderly, and very elderly) for selected pesticide residues in crop samples collected in the period 2017-2019. Risk is the quotient between the value of the exposure and its reference $(A D I)$. If the quotient is higher than 1 , it means that the limit has been exceeded and indicates that a certain risk exists. ADI exceedance was calculated with deterministic modeling. " $n$ " means the number of person 
threshold for children at an average residue concentration of $0.025 \mathrm{mg} \mathrm{kg}^{-1}$ it is necessary to consume (mathematically) at least seven tomatoes daily. In the case of adults, thirteen tomatoes would be required. These are consumption data that are higher than real consumption. However, the minimal chronic risk is obtained when children consume daily 1.5 tomatoes and adults 2.6 tomatoes. Only one adult (0.4\%), claimed having consumed that amount of tomatoes (three tomatoes).

The deterministic assessment of dietary risk from rice consumption (Table 4) showed that there is a negligible risk for every stratum. The results were as expected, based on the results from other researchers, who mentioned that some pesticides can be removed through milling, cleaning, washing, and cooking processes, which leads to reduced exposure (Đorđević and Đurović-pejčev 2016; Shakoori et al. 2018; Teló et al. 2017). This result may depend on the level of the traces present and if GAP is respected (Teló et al. 2015).

A study developed by Lehmann et al. (2017) in Burkina Faso identified a risk for $\lambda$-cyhalothrin (five times higher than the concentration found in this study), as well as for other AIs, in acute and chronic exposure scenarios for the consumption of vegetables. In the same study, they mention that the processing factor largely influences the risk, suggesting that a simple washing of vegetables with water can considerably reduce the risk of hazardous exposure. Other authors also mention how household processing (washing, peeling, and cooking) removes pesticide residues (bifenthrin, diafenthiuron, imidacloprid, and emamectin benzoate) from vegetables (Keikotlhaile et al. 2010; Scholz et al. 2016; Sheikh et al. 2012; Sheikh et al. 2015; Skovgaard et al. 2017; Tomer and Sangha 2013). In this way, processing factors on pesticide residues for vegetables and cereals play a very important role in risk assessment (Boitshepo Miriam Keikotlhaile 2011).

\section{Probabilistic}

Based on the fact that only methamidophos residues in tomato exerted risk for children and adults population in the maximum exposure scenario of the deterministic approach. Furthermore, there was only a small fraction of the population $(<20 \%)$ that consumed tomatoes. Also, the only low residue of methamidophos was detected in the tomato samples. Because of this, it was decided to carry out a more accurate and realistic probabilistic assessment analysis of the aforementioned strata.

The residue data of methamidophos could not be fitted directly to distribution, because of the many LOD values $(55 \%)$. Hence, the data were grouped into two groups, values above and below of LOD values. The first group was fitted to a distribution, following the rules of selection stable by the method and realistic according to the data. In this case, the most realistic distribution of the data was Invgauss, the option, Truncate minimum to 0 , was also used, to avoid that the function will move to negative values. After which the IF function in @RISK was used to generate a random distribution for the entire residue data.

The IF functions for the methamidophos residue distribution was:

$\operatorname{IF}(\operatorname{RAND}()<$ fraction of LOD,LOD, methamidophos residue distribution).

- methamidophos residue distribution:

RiskInvgauss(0.060643,0.02563,RiskTruncate(0,),RiskShift(- 0.004954),RiskName("methamidophos in tomato")).

- Fraction of LOD: 0.55 (LOD: $0.0003 \mathrm{mg} \mathrm{kg}^{-1}$ fresh mass).

The best-fitting distribution was also chosen for adult tomato consumption data. The data was divide into two, the percentage of zero consumption (84\%) and the adult tomato consumption values, with a response to Weibull distribution. The IF function used to generate the random distribution for the entire consumption data corresponds to the following function.

$\operatorname{IF}(\operatorname{RAND}()<$ fraction of 0,0 ,adult tomato consumption).

Adults tomato consumption:

RiskWeibull(1.58,0.001265,RiskTruncate(0,),Risk-

Shift(0.00013841),RiskName(“T”)).

In the case of children the IF function formulates is: $\operatorname{IF}(\operatorname{RAND}()<$ fraction of 0,0 ,average consumption value).

- The fraction of 0: 0.83 .

- Average consumption value: $0.0035 \mathrm{mg}$ food $\mathrm{kg}^{-1}$ $\mathrm{BW}$ day $^{-1}$.

Since only 5 children declared to have consumed tomatoes (low number of consumers) it is very limited to make a distribution. Instead of making a distribution, we opted for a fixed value (average) and then make an IF function.

From the probabilistic assessment of chronic exposure, shown in Supplementary Materials 8, it was found that unlike the results of the deterministic test, the daily intake of methamidophos (residue in tomatoes) was lower than the ADI in adults and children is very low. It only compromised $0.2 \%$ of that population, for average consumption. This implies that the dietary risk for the evaluated strata can be negligible. Considering that the probabilistic analysis is more precise than the deterministic one, it can be assumed that there was no risk at all from the consumption of tomatoes with methamidophos residues at the concentrations found and reported tomato consumption.

Out of these results, based on this case study in Sancti Spíritus, Cuba, and because the overall consumption of 
vegetables studied is low, it appears that the possible risk of pesticide residues in vegetables and rice is quite low. However, the work presents some weaknesses, which may also be responsible for the results obtained and which should be corrected in future research, to arrive at more realistic conclusions. The main weakness is the few variants and forms of consumption of the vegetables evaluated (e.g., tomato only raw), and the low number of foods studied.

To account for the study limitation, it could be proposed to evaluate the exposure of a typical Cuban daily recipe. Also consider different scenarios such as rural and urban, as well as seasonal crops. In this way, it would be possible to have a better idea of which crops, per season, in which stratum, and which active ingredients would require more attention, to keep consumers out of risks. Regardless of ensuring that good agricultural practices are followed, monitoring MRL values and advising farmers on the toxicity of the active ingredients they use and how to use them.

\section{Conclusions}

Most of the detected active ingredients (AIs) in the analyzed samples were insecticides and fungicides. Herbicides were almost absent. One-quarter of the quantified residues exceeded their corresponding maximum residue limit. In the deterministic assessment, only methamidophos in tomato samples for the maximum scenario in children and adult strata show a potential risk. No risk was found for the rest of the scenarios and strata. When more representative assumptions (median) and higher tomato consumption were assumed, the deterministic assessment found no chronic risk in children and adults due to methamidophos present in the tomato samples. The probabilistic risk assessment concerning methamidophos exposure in tomato for children and adult strata also showed negligible risk. Although the risk of exposure was not prominent, the presence of AIs at concentrations above the MRLs remains a problem. In the case of any government intervention where increased consumption of vegetables is considered, the use of pesticides in quantities exceeding those allowed could pose a problem. However, several weaknesses in the study limit a more accurate result. Such as few foods studied and consumption variants, like the type of food (raw or processed), of those studied. To improve a further accurate risk assessment for Cuban consumers it is important to have data on a more regular diet and food consumption varieties. In further research, this data could be collected so that the risk assessment is repeated. As seen in interviews with farmers, some pesticides that are frequently used in Cuba are not investigated in this work. In the future, exposure could be better determined when the dataset includes the consumption of fruits, grains, roots, and tubers and drinking water (which is treated frequently with temephos).

\section{Supplementary Information}

The online version contains supplementary material available at https://doi. org/10.1186/s40550-021-00081-2.

\begin{abstract}
Additional file 1: S1. MS/MS-transitions, applied collision energy and dwell time for the active ingredients analyzed in the study. S2. Vegetable and rice consumption data for the evaluated strata obtained from the consumption survey and used in the deterministic and probabilistic risk assessment. S3. Technical explanation of @Risk. S4. Vegetable and rice samples with pesticide residues detected by LC-MS/MS in 2017, 2018, and 2019. In certain cases, pesticide residues are detected but lay under the limit of quantification $(0.001 \mathrm{mg} \mathrm{kg}-1)$ and are therefore reported as "<LOQ". "*" Indicates lower limit of analytical determination (default value). "CoV" indicates the coefficient of variation. "e" Indicates exceedances of MRL values. S5. Vegetable and rice samples with pesticide residues detected by GC-ECD in 2017, 2018, and 2019. In certain cases, pesticide residues are detected but lay under the limit of quantification (0.01 $\mathrm{mg} \mathrm{kg}^{-1}$ ) and are therefore reported as "<LOQ". "**" Indicates lower limit of analytical determination (default value). "CoV" Indicates the coefficient of variation. "e" Indicates exceedances of MRL values. S6. Residue data of the active ingredients selected for the deterministic consumption exposure and risk assessment. S7. Deterministic risk assessment for the chronic exposure of the consumer for samples collected in the period 2017-2019. S8. Probabilistic assessment of chronic risk for children and adults due to the consumption of tomato and its methamidophos residue. Exposure and ADI values are defined. The ADI of methamidophos $\left(0.001 \mathrm{mg} \mathrm{kg}^{-1} \mathrm{BW}\right.$ day $\left.{ }^{-1}\right)$ is set on top of each graph. To the right of the $A D I$ value, it can be found the percentage of the population exposed to risk.
\end{abstract}

\section{Abbreviations}

ACN: Acetonitrile; ADI: Acceptable Daily Intake; ARfD: Acute Reference Dose; Als: Active ingredients; ALARA: As Low As Reasonably Achievable; BW: Body Weigh; EFSA: European Food Safety Authority; EU: European Union; GC/ ECD: Gas Chromatography with Electron Capture Detector; GAP: Good Agricultural Practice; HPLC: High-Performance Liquid Chromatography; LOD: Limit of Detection; LOQ: Limit of Quantification; LLMV: Lowest Limit of Method Validation; MoA: Mode of Action; MRLs: Maximum Residue Limits; MRM: Multiple Reactions Monitoring; PF: Processing factor; QUEChERS: Quick, Easy, Cheap, Effective, Rugged, and Safe; UPLC-MS/MS: Ultra Performance Liquid Chromatography-Tandem Mass Spectrometry

\section{Acknowledgments}

The author would like to thank Mr. Eris Perdomo's specialist in signage and crop protection of the Provincial Institute of Vegetal Health for the data provided for the realization of this study, as well as the help provided in the collection of samples and visit to the farms. Also a general thanks to the Provincial and Municipal Department of Varied Crops and Rice Industry.

\section{Authors' contributions \\ All the authors made significant contributions to the document and agree to its publication. The contributions were performed in the following order: Conceived and designed the experiments: ELD, MH, ORR, PS. performed the research: ELD, JDR, GC. Analyzed the data: ELD, JDR, MH, ORR. Contributed drafting of the manuscript; critical revision of the manuscript for important intellectual content; statistical analysis: ELD, MH, GC, AW, PS. The author(s) read and approved the final manuscript.}

\section{Funding}

This research did not receive any specific grant from funding agencies in the public, commercial, or not-for-profit sectors.

\section{Availability of data and materials}

All data generated or analyzed during this study are included in this article [and its supplementary information files]. Materials described in the manuscript, including all relevant raw data, will be freely available to any scientist wishing to use them for non-commercial purposes, without breaching participant confidentiality. On reasonable request, readers can ask for more information from the corresponding author in case of need. 


\section{Competing interests}

All the authors state that there are no conflicts of interest in this study.

\section{Author details}

${ }^{1}$ Study Center of Energies and Industrial Process, Sancti Spíritus University, Avenida de Los Mártires \#360, CP 60100 Sancti Spíritus, Cuba. ${ }^{2}$ Faculty of Bioscience Engineering, Ghent University, Ghent, Belgium. ${ }^{3}$ School of Technology, SRH - Hochschule Berlin, Ernts Reuter Platz 10, Berlin, Germany.

\section{Received: 26 November 2019 Accepted: 2 February 2021}

\section{Published online: 15 February 2021}

\section{References}

Alonso-Hernández CM, Tolosa I, Mesa-Albernas M, Díaz-Asencio M, CorchoAlvarado JA, Sánchez-Cabeza JA (2015) Historical trends of organochlorine pesticides in a sediment core from the Gulf of Batabanó, Cuba. Chemosphere 137:95-100. https://doi.org/10.1016/j.chemosphere.2015.05.044

Ayyogari K, Sidhya P, Pandit MK (2014) Impact of climate change on vegetable cultivation - A review. Int J Agri Environ Biotechnol 7(1):145-155. https://doi. org/10.5958/j.2230-732X.7.1.020

Barik SF, Ganguly P, Kunda SK, Kole RK, Bhattacharyya A (2010). Persistence behaviour of thiamethoxam and lambda cyhalothrin in transplanted paddy. Bulletin of Environmental Contamination and Toxicology 85(4):419-422. https://doi.org/10.1007/s00128-010-0101-2

Bernal E (2014) Limit of detection and limit of quantification determination in gas chromatography. Advances in Gas Chromatography, Xinghua Guo, IntechOpen, London, United Kingdom. https://doi.org/10.5772/57341

Brancato A, Brocca D, Ferreira L, Greco L, Jarrah S, Leuschner R, Medina P, Miron I, Nougadere A, Pedersen R, Reich H, Santos M, Stanek A, Tarazona J, Theobald A, Villamar-bouza L (2018) Guidance on use of EFSA Pesticide Residue Intake Model ( EFSA PRIMo revision 3). EFSA J 16(1):5147-5143. https://doi.org/10.2 903/j.efsa.2018.5147

Cochran WG (1977) Sampling Techniques (third edition). John Wiley \& Sons, Inc New York. https://archive.org/details/Cochran1977SamplingTechniques_201 703

Cuban National Bureau of Standards (2012) NC 902: 2012. Pesticides in foods general sanitary requirements. Oficina Nacional de Normalización. La Habana, Cuba. www.nc.cubaindustria.cu

del Puerto Rodríguez AM, Suárez Tamayo S, Palacio Estrada DE (2014) Effects of pesticides on health and the environment. Rev Cub Hig Epidemiol 52(3):372387

DG SANTE (2018) Guidance document on analytical quality control and method validation procedures for pesticide residues and analysis in food and feed, vol 46. European Commission Directorate General for Health and Food Safety, Brussel, Belgium.

Damalas CA, Koutroubas SD. (2018) Farmers' behaviour in pesticide use: A key concept for improving environmental safety. Current Opinion in Environmental Science \& Health 4:27-30

Donkor A, Osei-Fosu P, Nyarko S, Kingsford-Adaboh R, Dubey B, Asante I (2015) Validation of QuEChERS method for the determination of 36 pesticide residues in fruits and vegetables from Ghana, using gas chromatography with electron capture and pulsed flame photometric detectors. J Environ Sci Health B 50(8):560-570. https://doi.org/10.1080/03601234.2015.1028833

Đorđević T, Đurović-pejčev R (2016) Food processing as a means for pesticide residue dissipation. Pestic Phytomed (Belgrade) 31(3-4):89-105. https://doi. org/10.2298/PIF1604089D

European Commission. (2016). EU - Pesticides database. Plant. https://ec.europa. eu/food/plant/pesticides/eu-pesticides-database/public/?event=homepa ge\&language $=\mathrm{EN}$

European Food Safety Authority (2014) Guidance on the assessment of exposure of operators, workers, residents and bystanders in risk assessment for plant protection products. EFSA J 12(10):3874. https://doi.org/10.2903/j.efsa.2014.3 874

FAO/UNEP (2007) Rotterdam Convention. Operation of the prior informed consent procedure for banned or severely restricted chemicals. Draft Decision Guidance Document. ALACHLOR. Rome, Italy

FAO/UNEP. (2015). Rotterdam Convention. Operation of the prior informed consent procedure for banned or severely restricted chemicals. Decision Guidance Document Methamidophos

Fernandez M, Williams J, Figueroa G, Graddy Lovelace G, Machado M, Vasquez L, Perez N, Casimiro L, Romero G, Funes Aguilar F (2018) New opportunities, new challenges: harnessing Cuba's advances in agroecology and sustainable agriculture in the context of changing relations with the United States. Elem Sci Anth 6(1):76. https://doi.org/10.1525/elementa.337

Figueroa González ZI, Pérez-Consuegra N (2012) Tendencias en el uso de plaguicidas en el municipio Colón , Provincia Matanzas. Agr Orgán 18(2):1014 www.actaf.co.cu/revistas/revista_ao.../03TENDENCIAS.pdf

FRAC. (2018). FRAC code list (c) 2018: fungicides sorted by mode of action (including FRAC code numbering)

Gaceta Oficial de la República de Cuba, Ministerio de Finanzas y Precios, 15 Extraor 16 (2016)

García Álvarez, M. E., Tejeda González, G., \& Hernández Morales, A. (2014). Estudio de los factores críticos que inciden en el ciclo de la sostenibilidad alimentaria en Cuba (Yahima Ros). Instituto de Investigaciones en Fruticultura Tropical (iiFT). https://www.undp.org/content/dam/cuba/docs/Desarrollo humano/Palma-Agrocadenas/Factores Críticos-Libro.pdf

George L, Lenhart A, Toledo J, Lazaro A, Han WW, Velayudhan R, Ranzinger SR, Horstick O (2015) Community-effectiveness of Temephos for dengue vector Control : A systematic literature review. PLoS Negl Trop Dis 9(9):e0004006. https://doi.org/10.1371/journal.pntd.0004006

González Valiente ML, Conill Díaz TP (1999) Mortalidad por intoxicaciones agudas producidas por plaquicidas: Cuba, 1990-1994. Rev Cub Hig Epidemiol 37(2): 76-81 http://scielo.sld.cu/scielo.php?script=sci_arttext\&pid=\$1561-30031 999000200005\&lng=es\&nrm=iso\&tlng=es

Harel D, Fadida H, Slepoy A, Gantz S, Shilo K (2014) The effect of mean daily temperature and relative humidity on Ppollen, fruit set and yield of tomato grown in commercial protected cultivation. Agronomy 4:167-177. https://doi. org/10.3390/agronomy4010167

Hernández Contreras N, Chang Camero Y, Santana Suárez Y, Machado Martínez E, Martinez Izquierdo AM, Vazquez P, L. de la C. (2010) Uso deliberado de diversos productos para el control de Pediculus capitis ( De Geer , 1778 ), por padres o tutores de niños de escuelas primarias. Rev Cubana Med Trop 62(2):119-124 http://scielo.sld.cu/pdf/mtr/v62n2/mtr06210.pdf

Hernández Córdova N, Soto Carreño F (2012) Influence of three planting dates on growth and yield of cereal species grown in tropical conditions. Part I. maize (Zea mays L.). Trop Cult 33(2):44-49

Hernández Núñez, J., \& Pérez-Consuegra, N. (2012). Tendencias en el uso de plaguicidas en Batabanó , provincia Mayabeque. Agri Orgán, 18(1), 30-33. http://www.actaf.co.cu/revistas/revista_ao_95-2010/Rev2012-1/10plaguicida sBatabano.pdf

Hernández R, Sisinno A, Llanes MN (2003a) Residualidad de insecticidas en arroz. Oryza sativa L. Fitosanidad 7(2):59-61

Hernández R, Sisinno A, Ricardo C, Nela Llanes M, Linares C, Lazo A (2003b) Establecimiento de términos de carencia de plaguicidas en diferentes cultivos. Fitosanidad 7(4):27-37

Holland PT, Hamilton D, Ohlin B, Skidmore MW (1994) Effects of storage and processing on pesticide residues in plant products (pesticides report 31). Pure Appl Chem 66(2):335-356

IRAC. (2019). IRAC Mode of Action Classification Scheme. Version 9.3. https:www. irac-online.org/documents/moa-classification/

Jeger M, Bragard C, Caffier D, Candresse T, Chatzivassiliou E, Dehnen-Schmutz K, Grégoire J-C, Jaques Miret JA, MacLeod A, Navajas Navarro M, Niere B, Parnell S, Potting R, Rafoss T, Rossi V, Urek G, Van Bruggen A, Van Der Werf W, West J et al (2018) Guidance on quantitative pest risk assessment. EFSA J 16(8): 5350-5386. https://doi.org/10.2903/j.efsa.2018.5350

JMPR. (2015). Pesticide residues in food 2015. Joint FAO/WHO Meeting on Pesticide Residues (WHO and FAO (ed.)). World Health Organization, food and agriculture Organization of the United Nations

Keikotlhaile BM, Spanoghe P, Steurbaut W (2010) Effects of food processing on pesticide residues in fruits and vegetables: A meta-analysis approach. Food Chem Toxicol 48(1):1-6. https://doi.org/10.1016/J.FCT.2009.10.031

Keikotlhaile BM (2011) Influence of the processing factors on pesticide residues in fruits and vegetables and its application in consumer risk assessment. Ghent University, Belgium

Kiljanek T, Niewiadowska A, Semeniuk S, Gaweł M, Borz M (2016) Multi-residue method for the determination of pesticides and pesticide metabolites in honeybees by liquid and gas chromatography coupled with tandem mass spectrometry - honeybee poisoning incidents. J Chromatogr A 1435:100114. https://doi.org/10.1016/j.chroma.2016.01.045

Kim S-H, Lee C-H, Kim K-H, Jeong S-H (2016) Comparative estimation of exposure level and health risk assessment of highly produced pesticides to agriculture operators by using default dermal absorption rate or actual measurement 
values. Biomed Sci Lett 22(4):199-206. https://doi.org/10.15616/BSL.201 6.22.4.199

Lehmann E, Turrero N, Kolia M, Konaté Y, de Alencastro LF (2017) Dietary risk assessment of pesticides from vegetables and drinking water in gardening areas in Burkina Faso. Sci Total Environ 601-602:1208-1216. https://doi.org/1 0.1016/j.scitotenv.2017.05.285

Liang X, Liu X, Dong F, Xu J, Qin D, Li Y, Tian Y, Zhang Y, Han Y, Zheng Y (2013) Simultaneous determination of pyrimethanil, cyprodinil, mepanipyrim and its metabolite in fresh and home-processed fruit and vegetables by a QuEChERS method coupled with UPLC-MS/MS. Food Addit Contam Part A 30(4):713-721. https://doi.org/10.1080/19440049.2013.768777

Lista oficial de plaguicidas autorizados. Republica de Cuba, 422 (2008)

Markantonis M, van der Velde-Koerts T, Graven C, te Biesebeek J, Zeilmaker M, Rietveld A, Ossendorp B (2018) Assessment of occupational and dietary exposure to pesticide residues. EFSA J 16(S1):e16087, 8. https://doi.org/10.2 903/j.efsa.2018.e16087

Masiá A, Vásquez K, Campo J, Picó Y (2015) Assessment of two extraction methods to determine pesticides in soils, sediments and sludges. Application to the Túria River Basin. J Chromatography A 1378:19-31. https:// doi.org/10.1016/j.chroma.2014.11.079

Mekonen S, Lachat C, Ambelu A, Steurbaut W, Kolsteren P, Jacxsens L, Wondafrash M, Houbraken M, Spanoghe P (2015) Risk of DDT residue in maize consumed by infants as complementary diet in southwest Ethiopia. Science of The Total Environment 511:454-460

Mulet Pascual M (2017) Alimentación y análisis nutricional en La Habana bajo el prisma de la etnocontabilidad : el caso comparativo de las familias Vázquez y López. Cahiers Des Am Lat 84:125-146. https://doi.org/10.4000/cal.4547

ONEl. (2017). Ventas de productos agropecuarios. Indicadores seleccionados. http://www.one.cu/publicaciones/provincias_masinf/sancti spiritus.htm

ONEl. (2019). Oficina Nacional de Estadística e Información, Republica de Cuba. Indicadores seleccionados. http://www.one.cu/

Perdomo Hernández EE, Ramos Torres L, López Dávila E (2016) Efectos medioambientales en la provincia de Sancti Spíritus por el uso de plaguicidas químicos. Rev Márg 4(4):87-102

Rajapakse MKLK, Weerakkody NS, Lakshani PWY (2018) Quantification of pesticide residues vegetables using the QuEChERS method in selected. OUSL J 13(01): 29-42. https://doi.org/10.4038/ouslj.v13i1.7427

Räsänen K, Mattila T, Porvari P, Kurppa S, Tiilikkala K (2015) Estimating the development of ecotoxicological pressure on water systems from pesticides in Finland 2000-2011. J Clean Prod 89(May 2015):65-77. https://doi.org/10.1 016/j.jclepro.2014.11.008

Rawat S (2015) Food Spoilage : microorganisms and their prevention. Asian J Plant Sci Res 5(4):47-56

Registro Central de Plaguicidas. (2016). Lista oficial de plaguicidas autorizados. Republica de Cuba (M. de la A. (Minagri) (ed.)). Ministerio de la Agricultura (Minagri)

RIVM. (2015). List of processing factors to evaluate pesticide residues measured in The Netherlands. https://acceptatie.chemkap.rivm.nl/en/Topics/C/ChemKAP/ Fruit_and_Vegetables/Processing_factors

Roberts JR, Routt Reigart J (2013) Recognition and management of pesticide poisonings (6th). Office of Pesticide Programs, U. S. Enviromental Protection Agency. Washington, DC. United State of America. http://www2.epa.gov/ pesticide-worker-safety\%0A?????

Scholz R, Herrmann M, Michalski B (2016) Compilation of processing factors and evaluation of quality controlled data of food processing studies. J Verbr Lebensm:12. https://doi.org/10.1007/s00003-016-1043-3

Scholz, R., Van Donkersgoed, G., Herrmann, M. Kittelmann, A., von Schledorn, M., Graven, C., Mahieu, K., van der Velde-Koerts, T., Anagnostopoulos, Chris Bempelou, E., \& Michalski, B. (2018). Database of processing techniques and processing factors compatible with the EFSA food classification and description system FoodEx 2. Objective 3: European database of processing factors for pesticides in food. EFSA Support Publ, EN-1510, 50. doi: https:// doi.org/10.2903/sp.efsa.2018.EN-1510

Shakoori A, Yazdanpanah H, Kobarfard F, Shojaee MH, Salamzadeha J (2018) The effects of house cooking process on residue concentrations of 41 multi-class pesticides in rice. Iran J Pharm Res 17(2):571-584

Shamshiri RR, Jones JW, Thorp KR, Ahmad D, Man HC, Taheri S (2018) Review of optimum temperature, humidity, and vapour pressure deficit for microclimate evaluation and control in greenhouse cultivation of tomato : a review. Int Agrophysics 32:287-302. https://doi.org/10.1515/intag-2017-0005
Sheikh SA, Nizamani SM, Jamali AA, Mirani BN, Panhwar AA, Channa MJ (2012) Effect of household processing on the removal of pesticide residues in okra vegetable. J Basic Appl Sci 8(1):74-78

Sheikh SA, Panhwar AA, Khaskheli SG, Soomro AH, Khan S (2015) Methods for removal of pesticide residues in onion (Allium cepa L). Int J Biol Pharm Allied Sci 4(12):6668-6681

Skovgaard M, Encinas SR, Jensen OC, Andersen JH, Condarco G, Jørs E (2017) Pesticide residues in commercial lettuce, onion, and potato samples from bolivia - A threat to public health? Environ Health Insights 11:18-22. https://doi.org/10.1177/1178630217704194

Souza Chaves TV, Torequl Islam M, de Moraes MO, Oliveira Barros de Alencar MV, Vieira Gomes DC, Mendes de Carvalho R, Weider Maluf S, de Moura do Amaral FP, Correia Jardim Paz MF, Santos Cerqueira G, Lins Rolim HM, de Castroe Sousa JM, de Carvalho Melo-Cavalcante AA, Amaral de Moraes ME (2017) Occupational and life-style factors-acquired mutagenicity in agricworkers of northeastern Brazil. Environ Sci Pollut Res 24(18):15454-15461. https://doi.org/10.1007/s11356-017-9150-y

Sparks TC, Nauen R (2015) IRAC: mode of action classification and insecticide resistance management. Pestic Biochem Physiol 121:122-128. https://doi. org/10.1016/j.pestbp.2014.11.014

Teló GM, Marchesan E, Zanella R, de Oliveira ML, Lopes Coelho L, Martins ML (2015) Residues of fungicides and insecticides in rice field. Agron J 107(3): 851-863. https://doi.org/10.2134/agronj14.0475

Teló GM, Marchesan E, Zanella R, Peixoto SC, Prestes OD, de Oliveira ML (2017) Fungicide and insecticide residues in rice grains. Acta Scientiarum. Agronomy 39(1):9-15. https://doi.org/10.4025/actasciagron.v39i1.30594

Tomer V, Sangha JK (2013) Vegetable processing at household level : effective tool against pesticide residue exposure. IOSR J Environ Sci Toxicol Food Technol 6(2):43-53

Vega Bolaños LO, Arias Verdés JA, Conill Díaz T, González Valiente ML (1997) Uso de plaguicidas en Cuba, su repercusión en el ambiente y la salud. Rev Cubana Aliment Nutr 11(2):111-116

Wahid FA, Wickliffe J, Wilson M, Van Sauers A, Bond N, Hawkins W, Mans D, Lichtveld M (2017) Presence of pesticide residues on produce cultivated in Suriname. Environ Monit Assess 189(6):22. https://doi.org/10.1007/s10661-01 $7-6009-0$

\section{Publisher's Note}

Springer Nature remains neutral with regard to jurisdictional claims in published maps and institutional affiliations.
Ready to submit your research? Choose BMC and benefit from:

- fast, convenient online submission

- thorough peer review by experienced researchers in your field

- rapid publication on acceptance

- support for research data, including large and complex data types

- gold Open Access which fosters wider collaboration and increased citations

- maximum visibility for your research: over $100 \mathrm{M}$ website views per year

At BMC, research is always in progress.

Learn more biomedcentral.com/submissions 